

\section{Debilidades en el otorgamiento de créditos de una cooperativa de ahorro y crédito en}

Tingo María, Perú

Weaknesses in the granting of credit of a savings and credit cooperative in Tingo María, Perú

Dasmy Charlene Alegria Avellaneda

Universidad Nacional Agraria de la Selva, Tingo María. Perú.

\section{RESUMEN}

El estudio tuvo como objetivo identificar la deficiente evaluación y la ausencia de control interno que incrementan los riesgos operacionales. Los datos fueron obtenidos de la Agencia Tingo María de la Cooperativa de Ahorro y Crédito Tocache, El tipo de investigación fue cuantitativo - aplicada, con un nivel descriptivo - correlacional, diseño no experimental transversal. Se utilizó el proceso metodológico de recogida de datos de campo con las técnicas de encuesta, observación, entrevista y revisión documentaria, los resultados se contrastan con teorías encontradas de la revisión bibliográfica. Los resultados evaluados indicaron que la existencia de una deficiente evaluación y la ausencia de control interno incrementan los riesgos operacionales de la Agencia Tingo María de la Cooperativa de Ahorro y Crédito Tocache. Se evidenció que existe una relación significativa entre la deficiente evaluación y la ausencia de control interno con los riesgos operacionales, calificado como una correlación directa positiva con un grado de relación moderada. Se concluye que la deficiente evaluación y la ausencia de control interno, incrementan los riesgos operacionales en la Agencia Tingo María de la Cooperativa de Ahorro y Crédito Tocache.

Palabras clave: proceso, crédito, riesgo, debilidades, cooperativa. 


\begin{abstract}
The study aimed to identify the poor evaluation and lack of internal control that increase operational risks. The data were obtained from the Tingo María agency of Cooperativa de Ahorro y Crédito Tocache, The type of research was quantitative - applied, with a descriptive level - correlational, nonexperimental design - transversal. The methodological process of field data collection was used with the techniques of survey, observation, interview and documentary review, the results are contrasted with theories found in the literature review. It is concluded that the poor evaluation and the lack of internal control increase the operational risks in the Tingo María agency of the Cooperativa de Ahorro y Crédito Tocache
\end{abstract}

Keywords: process, credit, risk, weaknesses, cooperative.

\section{INTRODUCCIÓN}

El presente trabajo de investigación corresponde a las operaciones crediticias realizadas en la Agencia Tingo María de la Cooperativa de Ahorro y Crédito Tocache Limitada (COOPACT) durante el periodo 2018 - 2019. En tal sentido se describe las teorías y antecedentes orientados a los conceptos financieros específicamente al proceso crediticio. El diseño metodológico se circunscribe a la aplicación de las técnicas de observación directa, encuesta, entrevista y revisión documentaria, los resultados de la presente investigación nos permitieron demostrar la hipótesis planteada con las teorías vigentes en las cuales se basa la investigación y plantear sugerencias orientadas a minimizar los riesgos crediticios en la Agencia Tingo María de COOPACT-, las mismas que pueden ser generalizadas en empresas idénticas a nivel local, regional y nacional para luego plasmarlo en las conclusiones y recomendaciones. Ante el problema planteado ¿Cuáles son las debilidades que se presentan en el proceso crediticio dentro de las operaciones realizadas por la Agencia Tingo María de COOPACT?, se consideró como la hipótesis que la deficiente evaluación y la ausencia de control interno, incrementan los riesgos operacionales en la Agencia Tingo María de COOPACT, en tal sentido el objetivo de la investigación fue identificar la deficiente evaluación y la ausencia de control interno que incrementan sus riesgos. 


\section{METODOLOGÍA}

La investigación se llevó a cabo en la oficina central de la Cooperativa de Ahorro y Crédito Tocache Limitada (COOPACT) (Tocache, San Martin) y en su Agencia de Tingo María (Huánuco, Perú), entre octubre a diciembre de 2019. El nivel de investigación es descriptivo (Hernández et al., 2010) y el tipo de investigación es cuantitativo en cuanto a los datos, debido a que se recurre a datos numéricos reales. La investigación es de tipo aplicada porque se centra en el análisis y solución de problemas de varias índoles de la vida real, con especial énfasis en lo social (Lima y Luna, 2018). El diseño de la investigación es diseño no experimental - transversal, no se genera cambios intencionales dentro de las variables investigadas y los resultados se consiguieron en un determinado tiempo.

Debido al número limitado de colaboradores (15) que corresponden al administrador, asistentes de operaciones y otros trabajadores de la COOPACT, la presente investigación no requirió determinar el diseño muestral ya que la población sirvió como muestra, por lo tanto, no se utilizó la fórmula de la población finita, en resumen, el recojo de datos será al integro de la población.
Técnicas e instrumentos de recolección y tratamiento de datos

Análisis Documentario: Se considera la documentación que fue proporcionada por la COOPACT, la misma que fue revisada exhaustivamente por la investigadora.

Encuesta: Técnica que ha sido aplicada mediante la formulación de un cuestionario de preguntas relacionadas a los procesos propios de las actividades de la COOPACT. la que permitió obtener información del personal, sobre los procesos técnicos, gestión crediticia y gerencial con la finalidad de conocer la implementación de los procesos de control.

Entrevista: Esta técnica también fue aplicada en el proceso de recolección de evidencias y datos fidedignos de informantes clave. La técnica es ampliamente conocida y de uso común. También se aplicó el instrumento denominado cuestionario o guía de entrevista; es recomendable por que los datos obtenidos son de primera mano y aplicable a una población relativamente pequeña.

Observación Directa: Se aplicó la observación de los procedimientos administrativos del otorgamiento $y$ recuperación de créditos y sus implicancias gerenciales. 
Procesamiento y presentación de datos

Los datos conseguidos en el proceso de investigación fueron sometidos a las pruebas estadísticas actualizadas según la naturaleza del dato y la necesidad de la investigación. Se utilizó el software IBM SPSS Statistics 25.0 (Trial ID de Suscripción: 505824077) para la prueba de hipótesis.

\begin{tabular}{lll}
$\begin{array}{l}\text { Tabla } 1 \\
\text { Operacionalización de variables }\end{array}$ & \\
\hline \multicolumn{1}{c}{ Variable } & \multicolumn{1}{c}{ Indicador } & $\begin{array}{c}\text { Unidad de } \\
\text { medida }\end{array}$ \\
\hline VI1 = Deficiente evaluación $(\mathrm{X})$ & $\begin{array}{l}\mathrm{X} 1=\text { Precalificación } \\
\mathrm{X} 2=\text { Calificación } \\
\mathrm{X} 3=\text { Desembolso }\end{array}$ & $\%$ \\
VI2 = Ausencia del control interno & $\begin{array}{l}\text { Y1=Previo } \\
\text { Y2=Concurrente } \\
\text { (Y) }\end{array}$ & $\begin{array}{l}\text { Y3=Posterior } \\
\text { Z1=Estado de gestión }\end{array}$ \\
VD= Riesgos Operacionales (Z) & $\begin{array}{l}\text { Z2=Estado de resultados } \\
\text { Z3=Estado de flujo de } \\
\text { efectivo }\end{array}$ & $\%$ \\
\hline
\end{tabular}

Revisión documental

Durante el proceso de investigación se ha indagado la documentación relacionada con la información operacional y financiera de la Cooperativa de Ahorro y Crédito Tocache Limitada, siguiente:

a. Estado de Resultados a julio de 2019.

b. Reporte integrado de ingresos y gastos 2017 y 2018.

c. Reporte de Saldo de carteras de diciembre de 2018 a setiembre de 2019.

d. Informe de Auditoría de la revisión de expedientes de créditos desembolsados en la Agencia de Tingo María. e. Normativa General de Créditos de la COOPACT.

\section{RESULTADOS}

Se ha podido identificar diversas debilidades dentro del proceso crediticio, lo cual sirvió de motivación e inspiración para realizar el presente trabajo de investigación.

Detalle de las debilidades identificadas:

El destino de un crédito es genérico (no especifica en que va ser invertido el efectivo - tipo de crédito por consumo o personal).

Contratos de trabajo vencido (siendo requisito indispensable, ya que le sirve como aval del crédito para un crédito personal o de consumo).

Expediente para ser desembolsado sin la firma, ni sello del administrador de la Agencia.

Recibos de servicios como agua y luz vencidos hasta con un año de antigüedad (la norma indica que tiene que ser vigente y con excepción hasta un mes de vencimiento).

Las fotos adjuntadas no corresponden a la evaluación actual (fotos de evaluaciones antiguas).

En diversos expedientes de créditos, se detectó a una misma persona como referencia y aval. 
El destino del crédito está plasmado en el expediente, pero a la hora de interactuar con el socio y consultarle en que lo va a invertir el dinero es otro el destino del efectivo.

Tanto el aval (es) del crédito, recién se conocen dentro de la entidad (dando a entender que el asesor de negocio realiza estas maniobras incitado por su meta por cumplir).

La firma del socio o socios no coincide con el DNI dentro del expediente para ser desembolsado, siendo trabajo del asesor de negocios tomar las firmas en algunos documentos fuentes de información (siendo motivo de pérdida de tiempo para la Asistente de Operaciones de poner en práctica por varios minutos hasta obtener la firma que coincida con el DNI).

Expedientes para desembolsar dónde el socio titular del crédito hace mención que es separado (a) de su cónyuge, cuándo en la realidad si tienen pareja y es uno distinto al mencionado en el expediente de evaluación.

Se desembolsan los créditos sin la presentación del DNI por parte del cónyuge del socio titular del crédito.

Garante con antecedentes de morosidad en la cooperativa.

No se evidencia ni justifica los ingresos de otras actividades.
Créditos son avales cruzado (socio desembolsa y su prima es su aval, luego viceversa en un mismo día; la norma prohíbe ese acto).

No llenan el croquis para ubicación de la vivienda del socio.

Así mismo se puede asegurar que las debilidades del proceso crediticio influyen en las en las decisiones gerenciales, por lo que se puede decir que la correcta evaluación cuantitativa y cualitativa permiten mitigar la materialización del riesgo de crédito, Finalmente precisar que la ausencia de control interno influye en el incremento de riesgos de crédito en la Agencia Tingo María de COOPACT,

Así, según el análisis estadístico, las características de las variables de investigación no tienen distribución normal, y con la finalidad de soportar científicamente, se recurrió a la aplicación de la técnica estadística no paramétrica del Chi cuadrado, que mide la correlación o el grado de asociación entre dos variables y que no considera relaciones causales, con una medición de tipo nominal, y para pruebas independientes de una muestra menor que treinta $(n<30)$, en tal sentido, se planteó como hipótesis nula Ho: La deficiente evaluación y la ausencia de control interno, no incrementan los riesgos 
operacionales en Agencia Tingo María de la Cooperativa de Ahorro y Crédito Tocache Limitada, y como hipótesis alterna (H1): La deficiente evaluación y la ausencia de control interno, incrementan los riesgos operacionales en la Agencia Tingo María de la Cooperativa de Ahorro y Crédito Tocache Limitada.

Tabla 23

Prueba de Chi Cuadrado

\begin{tabular}{lccc}
\multicolumn{5}{c}{$\begin{array}{c}\text { Prueba de chi-cuadrado } \\
\text { Valor }\end{array}$} & gl & $\begin{array}{c}\text { Sig. } \\
\text { Asintótica } \\
\text { (bilateral) }\end{array}$ \\
\hline $\begin{array}{l}\text { Chi-cuadrado de } \\
\text { Pearson }\end{array}$ &, 667 & 4 &, 000 \\
Razón de \\
verosimilitudes \\
N de casos válidos
\end{tabular}

Figura 1. Curva de chi cuadrado de la hipótesis 1 (Fuente: SPSS V.25 bases de datos, encuesta y entrevista octubre 2019.

\section{DISCUSIÓN}

Ante la afirmación de que existen deficiente evaluación y la ausencia de control interno, incrementan los riesgos operacionales Agencia Tingo María de la Cooperativa de Ahorro y Crédito Tocache Limitada, se confirma la hipótesis planteada en la investigación, la evidencia se encuentra en las tablas 2 a 22. El nivel de correlación encontrada es $r=0,667$ con $4^{\circ}$ grados esto significa que se acepta la hipótesis.

En este sentido los resultados encontrados en la investigación concuerdan con lo manifestado con Ticse (2015) quien indica que la importancia de la efectiva administración del riesgo crediticio en el cumplimiento de objetivos y metas. Es así que la gestión eficaz del riesgo crediticio permite a las instituciones financieras a estar mejor preparados para evitar, mitigar y asumir las potenciales pérdidas por su exposición al riesgo, sin embargo, en el proceso de identificar un riesgo crediticio se encuentran algunas dificultades y por ende no se logran en su totalidad los objetivos". Efectivamente esta teoría se cumple cabalmente en nuestra unidad de análisis.

Asimismo, Zanabria (2017) menciona que el trabajo de investigación está referido a determinar la relación que existe en el proceso crediticio y la morosidad desde la percepción de los clientes de la Microfinanciera Trabajando Contigo E.I.R.L. en el año 2017 y concluye en que el proceso crediticio y la morosidad mantienen una relación, con un coeficiente de correlación de Pearson de 26,01, donde el deficiente proceso crediticio afecta el 
incremento de la morosidad que son resultado de la evaluación crediticia a cada cliente que se fija en la capacidad de pago. Por lo tanto, la política crediticia en la Microfinanciera se ve reflejada en el proceso crediticio ya que este es el primer proceso junto con otros indicadores lograr la reducción de la morosidad".

En este sentido lo manifestado por Zanabria (2017) concuerda con los resultados encontrados en nuestra investigación, con un tipo de investigación básica, diseño no experimental, transversal y cuantitativa; el nivel de investigación es correlacional; con un censo poblacional de 15 colaboradores de la COOPACT. dónde un mal proceso crediticio genera debilidades y por ende afecta en la toma de decisiones de la gerencia, éstos resultados estadísticamente están representados por la inferencia estadística Chi-Square Tests con un nivel de relación del $r=0,667$ considerado como una relación positiva moderada según la escala de la estadística.

En el presente trabajo se confirma que la variable problema propuesta en la hipótesis "La deficiente evaluación y la ausencia de control interno, incrementan los riesgos operacionales en la Cooperativa de Ahorro y Crédito Tocache Limitada, Agencia Tingo María" tiene un soporte científico a la luz de la realidad objetiva.
Por su parte Popper (1962) expresa que los datos empíricos son inequívocos, nunca ambiguos, y que todas las teorías se contrastan directamente con datos reales. Ambos conceptos teóricos permiten confirmar la hipótesis planteada en la presente investigación ya que la base teórica se soporta en los antecedentes previos.

En el presente trabajo se confirma que la variable problema propuesta en la hipótesis "La deficiente evaluación y la ausencia de control interno, incrementan los riesgos operacionales en la Cooperativa de Ahorro y Crédito Tocache Limitada, Agencia Tingo María" tiene un soporte científico a la luz de la realidad objetiva.

\section{CONCLUSIONES}

Existe deficiente evaluación y escaso control interno en el proceso crediticio, dentro de las operaciones realizadas por la Agencia Tingo María de COOPACT, afectando la gestión de riesgos.

Las deficiencias y debilidades del proceso crediticio detectadas por la Gerencia General, la Oficina de Control Interno, el Departamento de Contabilidad, el Área de Créditos y la misma Administración de la Agencia, afectan en las decisiones gerenciales dentro de la Agencia Tingo 
María de la Cooperativa de Ahorro y

Crédito Tocache Limitada,

El escaso control interno incrementa los riesgos de créditos en la Agencia Tingo María de la Cooperativa de Ahorro y Crédito Tocache Limitada,

\section{REFERENCIAS BIBLIOGRÁFICAS}

Cooperativa de Ahorro y Crédito Tocache Limitada. (2018a). Reporte integrado de ingresos y gastos 2017 y 2018.

Cooperativa de Ahorro y Crédito Tocache Limitada. (2018b). Informe de Auditoría de la revisión de expedientes de créditos desembolsados en la Agencia de Tingo María.

Cooperativa de Ahorro y Crédito Tocache Limitada. (2019.a). Estado de Resultados a julio de 2019.

Cooperativa de Ahorro y Crédito Tocache Limitada. (2019b). Reporte de Saldo de carteras de diciembre de 2018 a setiembre de 2019.

Cooperativa de Ahorro y Crédito Tocache Limitada. (s. f.). Normativa General de Créditos de la COOPACT.

Hernández, R., Fernández, C., y Baptista, P. (2010). Metodología de la Investigación (Sexta ed.). México:
McGraw-Hill/Interamericana

Editores, S.A. de CV.

IBM Corp. (2017). IBM SPSS Statistics for Windows, Version 25.0. Armonk, NY: IBM Corp. (Trial ID de Suscripción: 505824077).

Lima J., y Luna V. (2018). Implementación de talleres deportivos como estrategia para reforzar la práctica de valores en los estudiantes del $1^{\circ}$ y $2^{\circ}$ grado de secundaria de la institución educativa Coronel Casimiro Peralta de Alca, La Unión Are-quipa, 2018. [Tesis de pregrado, Universidad Nacional de San

Agustín]. http://repositorio.unsa.edu.pe/handle/ UNSA/7990

Popper, K. (1962), La Lógica de la investigación científica, Sánchez Zabala, V. (trad.), Madrid: Tecnos.

Ticse, P. (2015). Administración del riesgo crediticio y su incidencia en la morosidad de financiera Edyficar oficina especial - El Tambo. [Tesis de pregrado, Universidad Nacional del Centro del Perú]. http://repositorio.uncp.edu.pe/handle/ $\mathrm{UNCP} / 1620$

Zanabria, A. (2017). Relación del proceso crediticio y la morosidad desde la percepción de los clientes de la Microfinanciera Trabajando Contigo 
E.I.R.L. en el año 2017. [Tesis de pregrado, Universidad Continental]. https://repositorio.continental.edu.pe/ bitstream/20.500.12394/4892/1/INV _FCE_316_TE_Zanabria_Porras_20 17.pdf

\section{Contacto:}

Contadora Pública

Dasmy Charlene Alegria Avellaneda

dasmyalegria@gmail.com 